\title{
HOW THROUGH UNDERSTANDING OF ALPINE SKI NOVICES' ATTITUDES TOWARDS ALPINE SKIING MAKE THE ALPINE SKI SCHOOL MORE EFFICACEOUS
}

\author{
Vjekoslav Cigrovski ${ }^{1}$, Igor Božić ${ }^{2}$, and Nikola Prlenda ${ }^{1}$ \\ ${ }^{1}$ Faculty of Kinesiology, University of Zagreb, Croatia \\ ${ }^{2}$ Faculty of Physical Education and Sport, University of Banja Luka, Bosnia and Herzegovina
}

\section{SUMMARY}

The assumption of this study was that attitude towards alpine skiing and expectations of ski novices affect the level of achieved alpine ski knowledge. So, the aim was to determine correlation between alpine ski novices' attitude towards alpine skiing before the learning process and level of acquired knowledge after completion of structured alpine ski school program. 112 alpine ski novices (33 females and 79 males) participated in the study. All were tested on 26-item scale questionnaire for attitude evaluation and were included in 10-days alpine ski school program. After completion of ski school, all participants demonstrated eight elements of alpine ski technique which was used as a measure of acquired ski knowledge. Results showed statistically significant correlation between acquired alpine ski knowledge and attitude of ski novices towards alpine skiing $(r=.36)$. The most statistically significant correlation was determined between the level of learned parallel turn and attitude towards skiing $(r=.42)$. Our results point to importance of attitude towards alpine skiing and alpine ski learning.

Key Words: alpine skiing, learning process, attitude towards alpine.

\section{INTRODUCTION}

From the perspective of alpine ski novices, going to winter holidays and participation in alpine ski school program depends on the attitudes, which potentially influence their decision on further inclusion in this sport as well as success of alpine ski learning. Psychology defines attitude as a continuous positive and negative evaluation of people, objects and ideas (Petz, 1992). Attitudes are not inborn; they are formed during process of socialization and are connected to previous experience and often under influence of emotional experience (Aranson, Wilson, \& Akart, 2005). The alpine ski novices' attitude towards alpine skiing primarily depends on information the person is being exposed. In general, attitudes contain the information about the object of attitude, emotions and reactions toward the object of attitude, but when they are defined, usually one component dominates (Giddens, 2007). As the alpine ski novices' attitude towards alpine skiing can not be formed on personal experience, it is primarily bound to emotions and information from the environment. Attitude towards alpine skiing can also be changed, and this primarily happens after skiers have either positive or negative experience with skiing. Attitude of alpine ski novices towards alpine skiing can also be biased by the fear of injuries on ski terrains. This fear is mainly present due to potential loss of control over skies caused by weather conditions or crash with other skiers (Bouter, Knipschild, \& Volovics, 1989). Factors that can additionally either positively or negatively affect the attitude towards skiing are related to specific alpine environment. Namely, weather conditions in the mountains are variable; varying from ideal to extremely difficult for implementation of basic alpine ski school program. Mentioned conditions, especially during first hours or days of learning alpine skiing can have a great impact (again both positive and negative) on motivation for further alpine ski 
learning. Although the attitude of alpine ski novices is not much taken into account during alpine ski school programs, it can have a major effect on the level of achieved knowledge of alpine skiing. Learning effects will be that much greater if the student is motivated for learning and has a positive attitude. The aim of present research was to determine the correlation between the alpine ski novices' attitudes towards alpine skiing before participation in alpine ski school program and success of alpine ski learning after completion of structured basic alpine ski school.

\section{METHODS}

\section{Participants}

This investigation included 112 participants, of

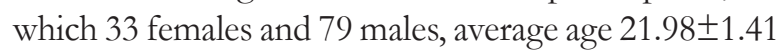
years. All participant were alpine ski novices, without prior own experience in alpine skiing.

\section{Variables}

The attitude towards alpine skiing was tested with 26-item questionnaire. This particular questionnaire was constructed to determine the alpine ski novices' attitude towards alpine skiing. Measured metric characteristics of the questionnaire enable its use in testing attitude towards alpine skiing (Cigrovski, Božić, Prlenda, Matković, \& Vlašić, 2012). The claims in the questionnaire were grouped into several categories and related to attitude towards skiing as a recreational sport, mountains during winter months, cold, physical activity in the open space, fear of injury, fear of speed, and finally fear of heights and slope. Participants were asked to grade each claim on a scale one to five, where one related to extremely negative, and five to extremely positive attitude. The questionnaire was not anonymous in order to be able to correlate results of the questionnaire with the level of achieved knowledge of alpine skiing after completion of structured program of alpine ski school. All participants gave informed consent prior to participation. Participants were graded by three independent judges upon completion of basic alpine ski school for the demonstration of learned elements of alpine ski technique, representing the new knowledge of alpine skiing. Elected were 8 elements of alpine ski technique; traversing left (KSL), traversing right (KSD), uphill turn to the left (ZKBL), uphill turn to the right (ZKBD), snowplough turn (PZ) basic turn (OZ), parallel turn (PZ), and short turn (V). Grades were used as an estimate for the level of new knowledge of alpine skiing. Grade one relates to the low level of alpine ski knowledge while five relates to high level of knowledge.

Investigational protocol: Firstly, all participants were asked to fulfil the questionnaire. Afterwards they were included in the 10-days basic alpine ski school learning program. All participants were then learning alpine skiing according to the same protocol, and similar conditions with respect to size of the group (10 participants per group), hours of learning during the day (4), hours of practicing/training during the day (2), quality of ski equipment, alpine ski instructors and ski terrains. Alpine ski technique consisted of more elements, but eight were chosen for the demonstration of alpine ski knowledge after completion of ski school.

\section{Statistical analysis}

Data obtained in this research were analyzed by correlation analysis with aim to determine relationship between alpine ski novices' attitude towards skiing and level of new ski knowledge. The mean grade of each participant on each element of alpine ski technique obtained by three independent judges was used as a final grade. The grade presenting overall ski knowledge was calculated as a mean grade from eight grades obtained for demonstration of elements of alpine ski technique. Statistical analysis included Pearson's coefficients to determine correlation between the alpine ski novices' attitudes towards alpine skiing and success of alpine ski learning. Data were analyzed with statistical package „SPSS for Windows 14.0“. Results were considered statistically significant if $p<$ .05 .

\section{RESULTS}

Results of descriptive parameters of questionnaire are presented in Table 1.

Basic descriptive parameters were calculated from grades obtained for evaluation of knowledge of alpine skiing. Level of new knowledge was calculated on basis of mean grade of all evaluated elements of alpine ski technique. Overall result of questionnaire for evaluation of attitude towards skiing was obtained by adding up results of all twenty-six items.

Afterwards we analyzed correlation coefficients between new ski knowledge and results obtained in questionnaire on attitude towards skiing.

Analysis of data presented in Table 3 shows the weak but statistically significant correlation between the attitude towards alpine skiing and level of acquired ski knowledge $(r=0.36)$. Correlation coefficient points to correlation between ski novices' attitude towards 
TABLE 1

Twenty-six-item scale for the evaluation of attitude towards alpine skïng.

\begin{tabular}{|c|c|c|c|c|c|}
\hline Claims & $M$ & Min & .00 & $M$ & $S D$ \\
\hline I don't like skiing because I fear of heights. & 112 & 2.00 & 5.00 & 4.59 & .84 \\
\hline $\begin{array}{l}\text { I don't like skiing because during winter time I prefer being in a } \\
\text { confined space. }\end{array}$ & 112 & 1.00 & 5.00 & 4.54 & .84 \\
\hline I like thrill, so I like skiing. & 112 & 1.00 & 5.00 & 4.21 & .89 \\
\hline $\begin{array}{l}\text { Just by watching skiing competitions I wished to be engaged in } \\
\text { alpine skiing. }\end{array}$ & 112 & 1.00 & 5.00 & 3.78 & 1.13 \\
\hline $\begin{array}{l}\text { I would like to go regularly to alpine skiing/winter vacation with } \\
\text { my family. }\end{array}$ & 112 & 1.00 & 5.00 & 4.19 & .96 \\
\hline $\begin{array}{l}\text { I don't want to learn alpine skiing out of fear of being worse than } \\
\text { my colleagues. }\end{array}$ & 112 & 2.00 & 5.00 & 4.68 & .75 \\
\hline I would like to become a ski instructor. & 112 & 1.00 & 5.00 & 3.41 & 1.17 \\
\hline I would like my kids to be good alpine skiers. & 112 & 1.00 & 5.00 & 4.29 & .82 \\
\hline I don't like skiing because I fear of avalanches. & 112 & 2.00 & 5.00 & 4.83 & .52 \\
\hline $\begin{array}{l}\text { I don't like skiing because I fear of injuries that would unable } \\
\text { participation in my sport. ......sport. }\end{array}$ & 112 & 1.00 & 5.00 & 3.89 & 1.16 \\
\hline I love the joys of winter so I like skiing & 112 & 1.00 & 5.00 & 3.95 & 1.11 \\
\hline I like skiing because it makes the adrenalin rise. & 112 & 1.00 & 5.00 & 4.22 & .94 \\
\hline $\begin{array}{l}\text { I don't like skiing because it takes place in unstable winter condi- } \\
\text { tions. }\end{array}$ & 112 & 2.00 & 5.00 & 4.29 & .90 \\
\hline I don't like skiing because of the discomfort caused by the cold. & 112 & 1.00 & 5.00 & 4.29 & 1.01 \\
\hline I don't like skiing, because I can't stand staying at high altitude. & 112 & 2.00 & 5.00 & 4.70 & .64 \\
\hline $\begin{array}{l}\text { I don't like skiing because of the feeling of uncertainty when using } \\
\text { the ski lifts. }\end{array}$ & 112 & 1.00 & 5.00 & 4.57 & .79 \\
\hline I don't like skiing because of fear of fall on ski slopes. & 112 & 1.00 & 5.00 & 4.21 & 1.09 \\
\hline I don't like skiing because I fear of solar radiation. & 112 & 3.00 & 5.00 & 4.71 & .54 \\
\hline Skiing is a fun activity. & 112 & 2.00 & 5.00 & 4.56 & .68 \\
\hline Fear of the ice surface distances me from skiing. & 112 & 2.00 & 5.00 & 4.40 & .91 \\
\hline I don't like skiing because I fear of a collision with other skiers. & 112 & 1.00 & 5.00 & 4.01 & 1.17 \\
\hline $\begin{array}{l}\text { If I didn't have to go to skiing during my university education I } \\
\text { would never go skiing. }\end{array}$ & 112 & 1.00 & 5.00 & 3.91 & 1.20 \\
\hline Exposure to wind on the ski slopes makes me not like skiing. & 112 & 2.00 & 5.00 & 4.60 & .75 \\
\hline $\begin{array}{l}\text { Improvement of ski techniques is more important to me than } \\
\text { "partying« at skiing. }\end{array}$ & 112 & 1.00 & 5.00 & 3.90 & 98 \\
\hline I don't like skiing because of fear of injuries. & 112 & 1.00 & 5.00 & 3.88 & 1.29 \\
\hline It scares me that I will be hurt in a fall with skis or poles. & 112 & 1.00 & 5.00 & 3.96 & 1.20 \\
\hline
\end{tabular}

Legend: N - Number of participants; Min - Minimum value; Max - Maximum value;

M - Mean; SD - Standard deviation.

skiing and acquired ski knowledge. Namely, if alpine ski novice has a positive attitude towards skiing, one can expect his/hers better achievement during beginning of alpine ski learning program (Table 3). The strongest statistical significance was obtained for the correlation between parallel turn and attitude towards skiing $(r=.42)$.

\section{DISCUSION AND CONCLUSION}

Alpine ski schools usually pay a lot of attention on choosing adequate program of learning basics of ski technique, methods of learning/teaching, on adequate ski equipment for each participant of ski school and conditions of learning. A lot less attention 
TABLE 2

Basic descriptive parameters for grades given on eight elements of ski technique, grades given for overall ski knowledge and results of attitude questionnaire

\begin{tabular}{lcrrrr}
\hline & $M$ & Min & \multicolumn{1}{c}{.00} & \multicolumn{1}{c}{$M$} & \multicolumn{1}{c}{$S D$} \\
\hline Traversing right & 112 & 2.00 & 5.00 & 3.80 & .74 \\
\hline Traversing left & 112 & 2.00 & 5.00 & 3.87 & .81 \\
\hline Uphill turn to the right & 112 & 2.00 & 5.00 & 4.05 & .75 \\
\hline Uphill turn to the left & 112 & 2.00 & 5.00 & 4.09 & .74 \\
\hline Snowplough turn & 112 & 2.00 & 5.00 & 3.45 & .84 \\
\hline Basic turn & 112 & 2.00 & 5.00 & 3.18 & .82 \\
\hline Parallel turn & 112 & 2.00 & 5.00 & 3.53 & .83 \\
\hline Short turn & 112 & 2.00 & 5.00 & 2.95 & .87 \\
\hline Knowledge of skiing & 112 & 2.25 & 4.81 & 3.61 & .53 \\
\hline Questionnaire results & 112 & 66.00 & 130.00 & 110.73 & 14.47 \\
\hline
\end{tabular}

Legend: N - Number of participants; Min - Minimum value; Max - Maximum value;

M - Mean; SD - Standard deviation.

TABLE 3

Correlation coefficients between ski knowledge at the end of investigation and the attitude towards alpine skiing.

\begin{tabular}{c|cccccccccc}
\hline & 1 & 2 & 3 & 4 & 5 & 6 & 7 & 8 & KOS & QR \\
\hline 1 & 1.00 & $.82^{* *}$ & $.53^{* *}$ & $.51^{* *}$ & .18 & $.27^{* *}$ & .14 & $.32^{* *}$ & $.70^{* *}$ & .18 \\
\hline 2 & & 1.00 & $.50^{* *}$ & $.51^{* *}$ & $.22^{*}$ & $.31^{* *}$ & $.21^{*}$ & $.29^{* *}$ & $.72^{* *}$ & $.24^{*}$ \\
\hline 3 & & & 1.00 & $.74^{* *}$ & $.30^{* *}$ & $.34^{* *}$ & $.37^{* *}$ & $.36^{* *}$ & $.77^{* *}$ & $.23^{*}$ \\
\hline 4 & & & & 1.00 & $.29^{* *}$ & $.39^{* *}$ & $.32^{* *}$ & $.33^{* *}$ & $.76^{* *}$ & $.20^{* *}$ \\
\hline 5 & & & & & 1.00 & $.19^{*}$ & $.32^{* *}$ & .01 & $.48^{* *}$ & .00 \\
\hline 6 & & & & & & 1.00 & $.65^{* *}$ & $.32^{* *}$ & $.66^{* *}$ & $.33^{* *}$ \\
\hline 7 & & & & & & & 1.00 & $.42^{* *}$ & $.66^{* *}$ & $.42^{* *}$ \\
\hline 8 & & & & & & & & 1.00 & $.59^{* *}$ & $.31^{* *}$ \\
\hline KOS & & & & & & & & 1.00 & $.36^{* *}$ \\
\hline QR & & & & & & & & & & 1.00 \\
\hline
\end{tabular}

Legend: 1 - Traversing right; 2 - Traversing left; 3 - Uphill turn to the right; 4 - Uphill turn to the left; 5 - Snowplough turn; $\mathbf{6}$ - Basic turn; 7 - Parallel turn; 8 - Short turn;

KOS - Knowledge of skiing; QR - Questionnaire results.

is given to characteristics and identity of pupils. This exactly could have a major impact on the better or worse alpine ski knowledge acquired through programs of ski school. Alpine ski novices' expectations, their attitudes and thoughts they have before starting alpine skiing most definitely influence effectiveness of alpine ski learning process in either positive or negative way. Some investigations determined significant correlation between attitude towards sport and physical activity and efficiency of learning new motor activity (Nieminen \& Varstala, 1999; Vlašić, 2010). One’s attitude towards particular sport or physical activity can have a crucial role on decision to participate or learn basics of sport. From the alpine ski instructors' perspective it is important to be informed about ski novices' attitude towards skiing before his/hers inclusion in the structured alpine ski learning program. This information can be important for realization of ski school program and finally for more efficient learning of alpine skiing. If an individual was satisfied with alpine ski learning in the alpine ski school, he/she will have a positive experience which will be shared with friends/ 
acquaintances. Particular alpine ski school is classified into a category of quality school which takes into consideration pupils' individuality, namely with respect to attitude, abilities and characteristics. During initial phases of alpine ski learning, just as like learning other motor activities, pupils' motivation contributes the level of new knowledge (Molanorouzi, Khoo, \& Riiser et al., 2014). Teacher by his/her attitude and proper teaching methods can definitely influence the pupil's motivation (Cigrovski, Radman, Matković, Gurmmet, \& Podnar, 2014). When alpine ski novice experiences pleasant moments in alpine ski school, then his/her attitude towards alpine skiing becomes positive. Alike, if a ski novice has an unpleasant experience during alpine ski school, for example crash or injury, his or hers attitude will become negative. Negative attitude change can be seen through enhanced caution or use of extra security equipment, such as helmet (Hasler et al., 2011). Moreover, sometimes negative experience in the beginning phases of alpine ski learning results in aborting skiing as a physical activity. It is well known that fear of injury has negative effects on process of learning or mastering sport/ physical activity (Cartoni, Minganti, \& Zelli, 2005). Our results show positive correlation between attitude towards skiing and learning alpine skiing during structured program of alpine ski school $(r=.36)$. During analysis of results one has to take into account the fact that learned alpine ski knowledge is the product of pupil's characteristics and abilities on one hand, and competence and expertise of ski instructors, conditions during ski learning (ski terrains, number of pupils pro group, hours of learning and exercising, weather conditions etc.), learning program and equipment on the other hand. All mentioned factors in larger or smaller extent influence the level of alpine ski knowledge. Factors of interest related to ski novice are his/her abilities and characteristics, and other important factors relate to program of learning and instructors' motivation, while combined they influence efficient alpine ski teaching (Cigrovski, Matković, \& Matković, 2010). As previously mentioned, alpine ski novice will form the attitude towards skiing even before the activity start. In order for the instructors to be informed about this attitude, it would be good to ask ski novices to fulfill the attitude questionnaire. The information in return could be helpful in better knowing and understanding pupils. Ski instructors could be in advance better prepared and according to pupils' attitude could adjust ways of ski teaching. For example, if ski novices accentuate the fear of hights, instructors could in their work dominantly use ski lifts, and avoid terrains with cable cars. Moreover, if ski novices express concern or fear of injury or crash, ski instructors can choose less frequent ski terrains and maximally insist on gradual progression of terrain slope. In that manner, instructor will improve safety of pupils, and people who expressed fear in the questionnaire will feel more relaxed. Also, if information from questionnaire shows pupils' interest in fast advances during alpine ski school or wish for learning specific techniques of alpine skiing, a ski instructor would be prepared accordingly. All mentioned will result in better motivation of pupils, and finally better learning of alpine skiing. By mentioned approach, instructors can adapt ski teaching according to attitudes of pupils. The down side of this investigation is primarily the sample of participants, while ski novices in this investigation consisted of merely motorically competent young people. It would be of interest to repeat the protocol of the investigation but on different participants' sample. If results would be comparable, one would with greater certainty claim the correlation between alpine ski novices' attitude towards skiing and success of alpine ski learning.

\section{REFERENCES}

Aranson, G., Wilson, T. D., \& Akart, R. M. (2005). Socijalna psihologija [Social psychology]. Zagreb, Croatia: Mate.

Bouter, L. M., Knipschild, P. G., \& Volovics, A. (1989). Personal and environmental factors in relation to injury risk in downhill skiing. International Journal of Sports Medicine, 10(4), 298-301. doi: 10.1055/s-2007-1024919; PMid: 2606596

Cartoni, A. C., Minganti, C., \& Zelli, A. (2005). Gender, age, and professional-level differences in the psychological correlates of fear of injury in Italian gymnasts. Journal of Sports Behavior, 28(1), 3-17.

Cigrovski, V., Božić, I. Prlenda, N., Matković, B., \& Vlašić, J. (2012). Construction of scale for evaluation of attitude towards alpine skiing. In S. Simović and V. Stanković (Eds.), 4th International scientific conference Anthropological aspects of sports, physical education and recreation (pp. 113-119). Banja Luka, Bosnia and Herzegovina: Faculty of physical education and sports. doi: 10.5550/SP.4.2012.012

Cigrovski, V., Matković, B., \& Matković, R. B. (2010). Can we make the alpine ski learning more efficient by omitting the snow-plough technique? SportLogia, 6(2), 51-57. doi: 10.5550 /sgia.1002051 
Cigrovski, V., Radman, I., Matković, B., Gurmmet, S., \& Podnar, H. (2014). Effects of alpine ski course program on attitudes towards alpine skiing. Kinesiology supplement, 46(2), 5-8.

Giddens, A. (2007). Sociologija [Sociology]. Zagreb, Croatia: Nakladni zavod Globus.

Hasler, R. M., Benz, J., Benneker, L., Kleim, B., Dubler, S., Zimmermann, H., \& Exadaktylos, A. K. (2011). Do alpine skiers and snowboarders wear protective equipment more often after an accident? Swiss Medical Weekly, 27, 141.

Molanorouzi, K., Khoo, S., \& Morris T. (2014). Validating the Physical Activity and Leisure Motivation Scale (PALMS). BMC Public Health, 14(1), 909. doi: 10.1186/1471-2458-14-909; PMid: 25182130; PMCid: PMC4168060

Nieminen, P., \& Varstala, V. (1999). Finnish dancers' attidudess towards folk, competitive ballroom, ballet and modern dance. Dance Research Journal, 31(2), 66-79. doi: $10.2307 / 1478332$

Petz, B. (1992). Psihologijski rječnike [Psychological dictionary]. Zagreb, Craotia: Prosvjeta.

Riiser, K., Ommundsen, Y., Småstuen, M. C., Løndal, K., Misvær, N., \& Helseth, S. (2014). The relationship between fitness and healthrelated quality of life and the mediating role of self-determined motivation in overweight adolescents. Scandinavian Journal of Public Health, 42(8), 766-772. doi: 10.1371/journal. pone. 0114732 .

Vlašić, J. (2010). Rąlike između studentica i studenata u plesnoj uspjeśnosti $i$ stavovima prema plesu

Differences between male and female students in dance performance and attitudes toward dance]. Unpublished doctoral dissertation, University of Zagreb, Kineziološki fakultet.

Received: September 20, 2014 Revision received: November 29, 2014

Accepted: December 11, 2014

Correspondence to: Vjekoslav Cigrovski, PhD

Kineziološki fakultet

Horvaćanski zavoj 15

10000 Zagreb

Croatia

Phone: +385 915442202

E-mail: vjekoslav.cigrov@kif.hr 